\title{
Intracellular Lipid Accumulation in Liver and Muscle and the Insulin Resistance Syndrome
}

\author{
Cristina Lara-Castro, MD, $\mathrm{PhD}^{\mathrm{a}}$ and W. Timothy Garvey, $\mathrm{MD}^{\mathrm{a}, \mathrm{b}}$ \\ a Department of Nutrition Sciences, University of Alabama at Birmingham, Birmingham, AL 35294-3360, \\ USA \\ b Birmingham Veterans Affairs Medical Center, Birmingham, AL 35233, USA
}

\section{Keywords}

insulin resistance; muscle fat; intramyocellular fat; hepatic steatosis; inflammation

\section{Insulin Resistance Syndrome}

Insulin resistance antedates the development of type 2 diabetes mellitus (T2DM) and also helps maintain the diabetic state. In non-diabetic individuals, insulin resistance commonly clusters with several anthropometric, metabolic, and hemodynamic traits including upper body fat distribution, glucose intolerance, dysfibrinolysis, relative hypertension, and dyslipidemia characterized by high triglycerides, low HDL cholesterol, and small dense LDL particles [1]. The term insulin resistance syndrome (IRS) or Metabolic Syndrome is used to refer to this cluster of interrelated traits, which predicts the future development of both T2DM and atherosclerotic disease [2]. While several sets of diagnostic criteria (e.g., ATPIII criteria) have been purported for clinical diagnosis, these diagnostic criteria can exhibit poor sensitivity for identifying patients with insulin resistance and dyslipidemia, and do not take in consideration the effect of age, race, ethnicity, and other variables [3]. Furthermore, the IRS incorporates multiple additional traits not recognized by established diagnostic criteria including markers of sub-clinical inflammation [4], altered circulating levels of factors derived from adipose tissue (adipokines) and the vasculature, and, importantly, intracellular lipid accumulation in liver and skeletal muscle, all of which are closely linked to the development of insulin resistance. Therefore, our use of the term insulin resistance syndrome will refer to the pathophysiological process responsible for the cardiometabolic trait cluster, without deference to Metabolic Syndrome diagnostic criteria. In this review, we will emphasize intrahepatocellular and intramyocellular lipid accumulation as components of the IRS, and the mechanisms responsible for the inter-relationships among ectopic fat deposition, insulin resistance, and associated metabolic traits.

Corresponding author for proof and reprints: W. Timothy Garvey, MD, Professor and Chair, Department of Nutrition Sciences, University of Alabama at Birmingham, 1675 University Blvd, Webb Building 232, Birmingham, AL 35294, (205) 934-6103 (office), (205) 934-7049 (fax), garveyt@uab.edu (email), Coauthor address: Cristina Lara-Castro, MD, PhD, Department of Nutrition Sciences, University of Alabama at Birmingham, 1825 University Blvd, Shelby 1230, Birmingham, AL 35294, (205) 996-4014 (office), (205) 996-5896 (fax), larac@uab.edu (email).

Publisher's Disclaimer: This is a PDF file of an unedited manuscript that has been accepted for publication. As a service to our customers we are providing this early version of the manuscript. The manuscript will undergo copyediting, typesetting, and review of the resulting proof before it is published in its final citable form. Please note that during the production process errors may be discovered which could affect the content, and all legal disclaimers that apply to the journal pertain. 


\section{Body Fat distribution, Insulin Resistance, and Obesity}

The pathophysiology of the IRS is likely to be multifactorial; however, the trait complex consistently involves some degree of relative insulin resistance [5,6]. It is likely that interactions involving age, behavior, environment, and genetic factors impact the relative severity of cardiometabolic risk factors that is associated with any given degree of insulin resistance. Obesity is also commonly implicated as a key pathogenic factor. While obesity can exacerbate insulin resistance and associated traits, only a small percentage of individual differences in insulin sensitivity can be attributed to differences in body mass index $[7,8]$. These relationships are illustrated in Figure 1A, which correlates body mass index (BMI) as a measure of generalized adiposity with maximally-stimulated glucose uptake rates assessed by hyperinsulinemic euglycemic clamp. While increasing obesity is associated with progressive decrements in insulin sensitivity, there is a high degree of inter-individual variation in insulin sensitivity such that lean or obese individuals can be either relatively insulin sensitive or resistant. The degree of correlation indicates that generalized obesity can explain approximately $8-15 \%$ of the variability in insulin sensitivity $[7,8]$. Thus, while general obesity is an important factor promoting insulin resistance, individual variation in insulin sensitivity largely exists independent of the degree of generalized obesity. What appears to be more important than generalized adiposity is where body fat is located. Aspects of fat distribution are prominent contributors to insulin resistance, including accumulation of fat in the omental or visceral compartment (i.e., upper body fat distribution), and intracellular fat in liver and muscle, all of which can exist independent of the degree of general adiposity. This is also illustrated in Figure 1 where increased intramyocellular lipid (IMCL) (Figure 1B), or waist circumference as an indicator of abdominal fat (Figure 1C), are more highly correlated with progressive insulin resistance (i.e., lower stimulated glucose uptake rates) than observed for BMI. The data in Figure 1 not withstanding, the relationships between insulin resistance, IMCL, and intrahepatocellular lipid (IHCL) are complex as will be discussed below in response to diet, exercise, weight loss, and racial identity.

\section{Intramyocellular Lipid (IMCL)}

Skeletal muscle accounts for the bulk of insulin-mediated glucose uptake, and impaired insulin action at the level of muscle is integral to the clinical manifestations of insulin resistance in T2DM and the IRS. Two characteristics of the insulin-resistant state include increased circulating free fatty acid levels, which in itself can induce insulin resistance in muscle [9], and impaired lipid oxidation in skeletal muscle [10]. The predicted functional consequence of increased FFA delivery and/or a defect in lipid oxidation would be an increase in intramyocellular lipid [11]. Skeletal muscle does contain an intracellular pool of stored triglyceride that exchanges with circulating FFA, and can be independently mobilized for lipid oxidation and contribute over half of fatty acids for oxidation in physiological settings [12, 13]. In older studies, muscle tissue triglycerides have been quantified using methods which do not distinguish between intramyocellular lipid (IMCL) and extramyocellular fat in muscle tissue, including biochemical extraction [14] and Hounsfield attenuation on computer tomography scans of thigh muscle $[15,16]$. These measures of total muscle lipid show high lipid content associated with insulin resistance in non-diabetic individuals $[14,16]$, type 2 diabetes [17,18], poorly controlled type 1 diabetes [18], aging [19], and coronary artery disease [20]. Investigators have more recently used proton NMR spectroscopy to quantify IMCL distinct from extramyocellular fat in muscle tissue [21-23]. These studies have shown that IMCL is consistently and highly correlated with insulin sensitivity, to a greater extent than visceral adiposity [24]. Importantly, the correlation between IMCL and insulin resistance can be independent of the degree of generalized obesity $[21,23,24]$. Increased intramyocellular lipid is similarly associated with insulin resistance in a variety of animal models [25,26], and in cultured L6 muscle cells where triglyceride loading was found to impair insulin-stimulated 
glucose transport [27]. Because of the consistent and exquisite nature of the correlation, several authors $[14,25]$ have advanced the hypothesis that IMCL accumulation and IMCL metabolites, such as diacylglycerol, long-chain fatty acyl-CoA species, ceramides, and oxidized lipid mediators are causally related to the induction of insulin resistance.

It is important to emphasize that accumulation of intramyocellular fat is not synonymous of insulin resistance. This situation is illustrated by the case of highly trained athletes who exhibit increased IMCL and who are highly insulin sensitive [29,30], although the intracellular locus and size of these lipid droplets may differ from IMCL accumulation in insulin-resistant subjects [31,32]. In this context, the elevated lipid levels reflect increased availability of free fatty acids required to meet the high oxidative requirements during exercise. In sedentary individuals, insulin resistance increases linearly with increases in IMCL. For this reason, it is important to control for exercise training when studying the relationship between IMCL and insulin resistance.

Interventions that manipulate IMCL demonstrate the close coupling of IMCL and the development of insulin resistance. For example, healthy subjects showed a decrease in insulin sensitivity and an increase in IMCL following the acute infusion of intravenous lipid [33,34], and conversely, long-term hypocaloric diets or malabsorption induced by biliopancreatic diversion led to enhanced insulin sensitivity and decreased IMCL [35-37]. These latter studies highlight the dynamic role of IMCL stores, and are reflective of an active mobilization of IMCL stores under conditions of caloric restriction. However, this also gives rise to the question of whether overall weight loss itself or depletion of IMCL is directly responsible for the improvement in insulin sensitivity. Two observations substantiate an important association between generalized obesity and insulin resistance. First, there is a strong epidemiological link between obesity and T2DM, and the second link is the observation that weight loss following hypocaloric feeding or bariatric surgery rapidly leads to marked increments in insulin sensitivity. These observations are somewhat at odds with the finding that generalized obesity is not a major factor accounting for individual variability in insulin sensitivity in cross-sectional studies (see Figure 1). Which is most relevant to insulin resistance, general obesity or IMCL? To address this issue, we evaluated the effects of short-term very-low-calorie-diet in both obese and type 2 diabetic subjects [38]. After 5 days, we found that the hypocaloric diet led to marked reductions in IMCL coupled with enhanced insulin sensitivity assessed by hyperinsulinemic clamp, with only minimal change in BMI and no statistically significant change in body fat mass measured by DEXA scan (Figure 2). Therefore, rapid amelioration of insulin resistance by VLCD can be explained by loss of IMCL in both non-diabetics and in T2DM in the absence of substantial changes in total body fat. These observations suggest that the amount of IMCL, rather than measures of generalized adiposity, might be more pathophysiologically relevant to insulin resistance.

Evidence has been accumulating that insulin resistance is accompanied by mitochondrial dysfunction in skeletal muscle and liver, and that this could be the proximal cause of impaired lipid oxidation and accumulation of IMCL [39-41]. Kelley et al have reported that muscle NADH-Q2 oxidoreductase activity (complex 1) is reduced in T2DM, reflecting decreased activity of the respiratory chain, and that mitochondria appeared smaller and damaged on EM in T2DM and obesity compared with lean controls [39]. Increased IMCL was also associated with impaired oxidative phosphorylation using ${ }^{31} \mathrm{P}$ magnetic resonance spectroscopy in insulin resistant offspring of T2DM patients [40]. Similarly, mitochondrial dysfunction has been related to increased IMCL and insulin resistance in aging [41], and the increase in hepatocellular lipid in Non-Alcoholic Steatohepatitis [42]. Furthermore, several cDNA microarray studies comparing differential gene expression in skeletal muscle from non-diabetic controls and T2DM patients [43-44], and comparing insulin sensitive and insulin resistant nondiabetics [45], have shown extensive down-regulation of genes encoding mitochondrial 
proteins. Our data are consistent with these observations, and indicate that there is reduced expression of genes relating to mitochondrial function in muscle from normoglycemic insulin resistant individuals and T2DM patients, and this includes reduced expression of key transcription factors that participate in mitochondrial biogenesis $[46,47]$.

In cross-sectional studies, insulin resistance in the elderly and in lean, insulin-resistant, normoglycemic offspring of type 2 diabetics is associated with IMCL accumulation and decreased mitochondrial oxidative capacity. Thus, it is possible that in some instances increased IMCL arises as a result of age-related or genetic defects affecting mitochondrial oxidative phosphorylation [41]. However, decreases in IMCL and improvement in insulin sensitivity can also occur independently of changes in mitochondrial capacity as demonstrated by Toledo et al [48]. These authors examined the effects of a weight loss diet with and without exercise. Both intervention groups experienced a similar degree of weight loss and a similar increase in insulin sensitivity; however, IMCL decreased only in the diet-alone subgroup and mitochondrial content and electron transport chain activity increased only in the diet plus exercise subgroup. These results are difficult to interpret with respect to IMCL and insulin sensitivity since diet and exercise have opposite effects on IMCL as discussed above, but do dissociate mitochondrial function from IMCL accumulation. Along these same lines, the study depicted in Figure 2 demonstrated that very-low-calorie-diet markedly reduces IMCL in both T2DM and non-diabetic subjects [38], which suggests that IMCL can be similarly manipulated in subjects with (i.e., T2DM) and without known mitochondrial dysfunction. In addition, the mechanistic link between IMCL and insulin resistance may relate to increased levels of IMCL metabolites such as diacylglycerol or long-chain fatty acyl-CoA. Overall, these studies indicate that IMCL stores dynamically respond to caloric manipulation, and, when present in excess, may impair insulin sensitivity.

\section{Intrahepatocellular Lipid (IHCL)}

Similarly to what has been described for skeletal muscle, lipid can accumulate abnormally in hepatocytes in the context of the IRS. Abnormal fat accumulation in the liver in the absence of heavy alcohol ingestion is referred to as non-alcoholic fatty liver disease (NAFLD), and is manifest as a wide spectrum of hepatic dysfunction. While hepatic steatosis is most often nonprogressive, smaller numbers of patients progress to more severe liver disease including NonAlcoholic Steato-Hepatitis (NASH) with or without fibrosis, cirrhosis, and occasionally hepatocellular carcinoma. In cross-sectional studies, overall adiposity (i.e., BMI) is positively associated with the prevalence of NAFLD and extent of steatosis, but these relationships are explained in part by visceral adiposity [49]. In fact, intra-abdominal fat mass is strongly correlated with fat accumulation in liver independent of overall adiposity [50]. Visceral fat and IHCL appear to be causally related in what has been called the visceral/portal hypothesis; that is, expanding visceral fat increases the availability of fatty acids and inflammatory adipokines in the portal circulation with direct delivery to the liver. In turn, the resulting accumulation of IHCL results in impaired insulin-mediated suppression of hepatic glucose production and dyslipidemia characterized by elevated hepatic VLDL-triglyceride secretion combined with elevated HDL-cholesterol clearance. Predictably, given the high degree of association between visceral fat expansion with both NAFLD and IRS, elevated IHCL content is associated with insulin resistance and the associated cluster of cardiometabolic risk factors including dyslipidemia, relative hypertension, and insulin resistance in liver and skeletal muscle compared to weight-matched controls [51,52].

Even though insulin resistance is highly correlated with IHCL, there are several instances in which insulin resistance develops independent of the degree of fat accumulation in liver, and insulin resistance alone does not appear sufficient for the development of steatosis or NASH. This is evidenced by the fact that patients with severe insulin resistance due to insulin receptor 
mutations or anti-receptor antibodies [53,54] do not develop NASH, hypertriglyceridemia, hepatomegaly, or abnormal liver function tests. Similarly, adiponectin knock-out mice exhibit impaired insulin signaling in the liver leading to hepatic insulin resistance, decreased hepatic expression of lipogenic genes such as SREBP-1 and SCD-1, increased adipose tissue mass, and systemic inflammation as indicated by increased TNF- $\alpha$ levels [55], but do not accumulate triglyceride in liver. Interestingly, in adiponectin plus leptin double-knockout [adipo(-/-)ob/ ob] mice, insulin resistance was still present even though downregulation of SREBP-1 and SCD-1 was no longer observed and hepatic triglyceride content was significantly increased [56]. These data indicate that insulin resistance occurring as a result of adiponectin deficiency may be related to factors other than the accumulation of liver or muscle fat per se.

\section{Pathophysiology of Excess IMCL and IHCL Role of Adipose Tissue}

Adipose tissue plays a key pathogenic role in abnormal intracellular accumulation of lipid in liver and muscle. Adipose tissue promotes the IRS through excessive release of free fatty acids and altered secretion of adipokines, which act both as paracrine factors in adipose tissue and as endocrine factors influencing systemic glucose and lipid metabolism. These adipokines include, but are not limited to, adiponectin, leptin, plasminogen activator inhibitor (PAI-1), resistin, tumor necrosis factor $\alpha$ (TNF- $\alpha$ ), and other inflammatory factors including interleukins 6, 8, 10, and macrophage chemo attractant factor 1 (MCP-1). In fact, it is known that autocrine/paracrine cross-talk among adipocytes, stomal-vascular cells, and macrophages actively participate in adipose tissue function and adipokine secretion. Expansion of visceral adipose tissue is associated with infiltration of macrophages, decreased adiponectin secretion, and release of inflammatory factors and, conversely, weight loss is associated with a reduction in adipocyte size, macrophage infiltration, and secretion of inflammatory factors, and an increase in adiponectin secretion [57,58]. Accumulating evidence suggests that these secreted factors induce skeletal muscle and hepatic insulin resistance, and may constitute a mechanistic link between increased visceral fat, insulin resistance, and accumulation of IHCL and IMCL. Over the past 10 years, accumulating data has substantiated this 'adipocentric' view of the development of insulin resistance and associated metabolic traits.

Examination of two extreme pathophysiological states affecting body fat, namely lipodystrophy and obesity, highlight the interactions between adipose tissue and ectopic lipid accumulation in liver and muscle. On one end of the spectrum, various forms of lipodystrophy lead to marked insulin resistance and full manifestation of the metabolic syndrome, together with pronounced accumulation of IHCL and IMCL. Most patients with adipose tissue atrophy exhibit leptin deficiency together with steatosis and intracellular triglyceride accumulation in several organs. Mouse models of leptin deficiency or leptin resistance also exhibit the full metabolic syndrome early in life, including hyperlipidemia, elevated free fatty acids, and steatosis of liver, heart, skeletal muscle, and pancreatic islets even on low-fat diet [Reviewed in 59]. Thus, an intact functional leptin axis is necessary to prevent accumulation of lipids in non-adipose tissues which are not adapted for triglyceride storage. Moreover, leptin has been effective in treating the increased hepatic lipid accumulation and insulin resistance in patients with severe lipodystrophy [60]. The other end of this spectrum is represented by adipose tissue expansion due to positive energy balance and obesity, although, as discussed above, obesityrelated induction of insulin resistance with IHCL and IMCL accumulation occurs when there is a relative increase in fat distribution to the visceral compartment. Obesity is also marked by leptin resistance. Thus, both expansion (i.e., obesity) and pathological contraction (i.e., lipodystrophy) of adipose tissue are characterized by ectopic fat accumulation in muscle and liver cells, insulin resistance, and the IRS trait complex, and further by either leptin deficiency or resistance. These observations strongly support the hypothesis that events in adipose tissue 
and the ectopic accumulation of fat in liver and muscle are closely coupled with each other and the development of insulin resistance.

It is also instructive to consider these interactions in response to thiazolidinediones (TZDs) [61], which act to enhance insulin sensitivity and are widely used for the treatment of T2DM. As PPAR $\gamma$ agonists, these drugs exhibit a wide range of metabolic effects including an ability to promote adipocyte development and differentiation [62]. In humans, effects on adipocytes are manifested by a shift of adipose tissue mass away from the visceral compartment with expansion of the subcutaneous compartment, accompanied by an increase in the number of small adipocytes and alterations in adipose tissue cell composition and function [63]. At the same time, TZDs reduce lipid content in both hepatic and muscle cells, and are being investigated for therapeutic efficacy in NAFLD. Thus, TZDs work in part by augmenting the fat-storing capacity in subcutaneous adipose tissue coupled with reduced fat storage in the visceral compartment and in ectopic locations such in liver and skeletal muscle. From the discussion above, physiological responses to obesity, lypodystrophy, leptin action, and TZD treatment all demonstrate the relationship between lipid storage capacity in adipose tissue and accumulation of IMCL and IHCL in insulin resistant states.

\section{Role of Inflammation}

Another common feature of pathophysiological states characterized by the accumulation of fat in non-adipose tissues and insulin resistance is systemic inflammation, which is observed at both the systemic level and in adipose tissue. This applies, for example, to both the extremes of lipodystrophy and obesity. Lipodystrophic patients exhibit increased circulating concentrations of TNF- $\alpha$ and an increase in macrophage infiltration in adipose tissue [64,65]. Similarly, obesity, particularly when accompanied by visceral fat redistribution, is characterized by increased macrophage infiltration and over-expression of inflammatory cytokines and chemokines as discussed above. Thus, it is tempting to hypothesize that adipose tissue derived inflammation may contribute to the development of ectopic fat accumulation and subsequent insulin resistance. Several lines of evidence support that hypothesis. Inflammatory cytokines such as TNF- $\alpha$ and IL-6 have been linked to the development of insulin resistance, the Metabolic Syndrome, and T2DM. Interestingly, in adipose tissue, interstitial IL-6 concentrations are considerably higher than circulating plasma levels, underscoring a potential role as paracrine regulator of adipose tissue [66]. Indeed, inflammatory cytokines such as IL- 6 and TNF- $\alpha$ impair differentiation, reduce lipid accumulation, and increase lipolysis in adipocytes, and also reduce expression of several genes important for substrate metabolism and insulin action [67]. Thus, these cytokine-mediated actions adversely affect adipose tissue storage capacity, rendering circulating lipids available to accumulation in non-adipose tissues. Furthermore, adiponectin, an adipokine with anti-inflammatory action, is reduced in states of both lipodystrophy and obesity, and is an important autocrine/paracrine regulator of adipose tissue. In 3T3-L1 fibroblasts, adiponectin promotes cell proliferation and differentiation by augmenting programmed gene expression responsible for adipogenesis, and increases lipid content and insulin responsiveness of the glucose transport system in adipocytes [68]. Therefore, orchestrated paracrine/autocrine effects of anti- and pro-inflammatory cytokines on development and function of adipose tissue are able to diminish the storage capacity of adipose tissue, favoring the accumulation of lipids in non-adipose tissue compartments.

In humans, the extent of adipose tissue inflammation is correlated with liver fat. In women of varying degrees of obesity, adipose tissue gene expression of macrophage markers was closely and positively correlated with liver fat content, and inversely correlated with whole body insulin sensitivity, and these associations were independent of total body fat [69]. To further explore the observation that adipose tissue is inflamed in individuals with increased IHCL 
independent of obesity, Kolak et al studied obese women with high and low liver fat content, but similar in age and body fat mass [70]. In this study, adipose tissue expression levels of plasminogen activator inhibitor-1, the macrophage marker CD68, and two chemokines, monocyte chemoattractant protein-1 and macrophage inflammatory protein-1alpha, were all significantly increased, and expression of peroxisome proliferator-activated receptor-gamma and adiponectin decreased in the high liver fat group. Furthermore, lipidomic analysis in adipose tissue revealed several differences between the groups, with the most striking being increased concentrations of triacylglycerols (particularly long-chain) and ceramides in the high liver fat group. Interestingly in this study, subjects in both groups also exhibited similar levels of abdominal fat (intra-abdominal and subcutaneous) and circulating free fatty acids, underscoring the distinct connection between adipose tissue inflammation and liver fat. Overall, these studies indicate that the degree of adipose tissue inflammation rather than the level of adiposity is more closely related to liver fat, and suggest that inflammatory changes in adipose tissue mediate liver fat accumulation, or that a common etiological factor regulates both liver fat and inflammation in adipose tissue.

\section{Role of Muscle and Liver Tissue: lipid droplets/perilipin}

Intracellular lipid accumulation in muscle and liver (i.e., in locations other than adipose tissue) reflects a surplus intracellular source of fatty acids in excess of the oxidative needs of the cell, due either to a limited capacity for triglyceride storage in subcutaneous adipose tissue resulting in the need for "ectopic" triglyceride distribution in other organs, and/or impaired cellular mechanisms regulating lipid storage and utilization. We have highlighted the critical role of adipose tissue in the development of insulin resistance and in the accumulation of IMCL and IHCL. However, recent studies have also demonstrated the importance of molecular factors intrinsic to muscle and liver cells involved in the regulation of lipid turnover. Intracellular lipid droplets are active deposits coated with several proteins that act as surfactants at the lipid droplet surface and that participate in the packaging of lipids and access of tissue lipases to the triglyceride contained in these droplets. These coating proteins belong to a family of proteins that share homologous sequences and domains including perilipin, adipose differentiation related protein (ADFP), and tail interacting protein, which in aggregate are referred to as PAT proteins. These proteins are ubiquitously produced in adipose and non-adipose tissues and modulate lipid droplet turnover predominantly by affecting lipolysis [71]. In mouse hepatocytes, down regulation of two PAT proteins, ADFP and Tip47, reduced lipid content due to a net increase in lipolysis; these changes were accompanied by a decrease in adipose triglyceride lipase (ATGL) in the hepatocytes and the induction of insulin resistance as reflected by decreased stimulation of Akt phosphorylation [71]. Thus, down-regulation of PAT proteins is sufficient to induce insulin resistance in liver cells due to an increase in lipolytic rate and/or a mismatch between fatty acid availability and utilization. Perilipin-null mice are lean but display aberrant adipocyte lipolysis, enhanced leptin production, resistance to dietinduced obesity, and peripheral insulin resistance [72,73]. Collectively, these studies indicate that proteins regulating lipid turnover (i.e., PAT proteins) in non-adipose cells can play a primary role in the regulation of ectopic fat, and that their function may partially explain the connection between IMCL and IHCL accumulation and the development of insulin resistance independent of overall adiposity [71]. Another family of proteins that can regulate ectopic fat accumulation is the lipin family [Reviewed in 74]. The most prominent of these proteins is lipin-1, identified by positional cloning of the mutant gene underlying lipodystrophy in the fatty liver dystrophy (fld) mouse. Lipin 1 deficiency results in lipodystrophy involving visceral and subcutaneous white adipose tissue and interscapular brown adipose tissue, and are also characterized by insulin resistance [75]. In contrast, fat-specific hyperexpression of a lipin 1 transgene results in increased triglyceride storage in adipose tissue and increased insulin sensitivity, despite the development of obesity. In humans, lipin 1 expression levels in adipose tissue are positively correlated with insulin sensitivity, and inversely correlated with 
inflammatory cytokine expression and intramyocellular lipid [76,77]. Lipin 1 plays an important enzymatic role in triglyceride and phospholipid biosynthesis as a phosphatidate phosphatase, and also acts as an inducible transcriptional coactivator in conjunction with peroxisome proliferator-activated receptor $\gamma$ (PPAR $\gamma$ ) coactivator- $1 \alpha$ and PPAR $\alpha$. Through these activities, lipin-1 influences lipid metabolism and glucose homeostasis in diverse tissues including adipose tissue, skeletal muscle, and liver. These data from mouse and human studies suggest a role for lipin 1 in directing lipid to the appropriate storage site in adipose tissue, with concomitant reductions in lipid accumulation in tissues such as muscle and liver.

\section{Racial Differences in the Relationships between IMCL, IHCL, and Insulin Resistance}

The prevalence of T2DM is growing globally at an alarming rate [78], and this problem is particularly severe among individuals of African descent. Results from the Atherosclerosis Risk in Communities (ARIC) Study of over 10,000 Americans reveal that African American (AA) women and men have a 2.4-fold and 1.5-fold greater incidence of T2DM, respectively, than their European American (EA) counterparts [79], which is at least partially attributable to the increased prevalence of obesity in AA [80]. Surprisingly, however, AA have significantly lower levels of visceral fat than their EA, despite a higher prevalence of insulin resistance and T2DM. Studies of ethnic differences in fat distribution show that, even after controlling for total fat and BMI, African American women have significantly less visceral fat than European American women [81], differences that persist even after significant weight gain [82] and weight loss [83]. Thus, it appears that AA exhibit impaired insulin resistance at a lower threshold of visceral fat accumulation when compared with EA and Hispanics. Similarly, AA youth carry less visceral fat than their EA peers, indicating that these differences are manifest early in life [84]. These observations indicate that race can impact the relationships between body fat distribution and insulin sensitivity. In fact, multiple aspects of the IRS trait cluster are affected in AA. Europid populations, of course, exhibit strong correlations between insulin resistance and upper body fat distribution, glucose intolerance, hypertension, and dyslipidemia. In contrast, in populations of predominant African background, elevated blood pressures, triglycerides, and HDL cholesterol can exist independent of insulin sensitivity $[85,86]$. These differences can be explained in part by the degree of African genetic ancestral admixture [87], and are also likely driven by interactions between genetic and shared environmental factors.

Racial differences are also apparent regarding the role of IMCL and IHCL in the development of insulin resistance and the IRS. We have metabolically characterized individuals of European and African ancestry and have found that, in EA, IMCL is consistently correlated with insulin sensitivity (Figure 3A) and measures of generalized and regional adiposity including BMI (Figure 3B), waist circumference, and trunk fat, whereas, in AA, IMCL varies in a manner that is independent of insulin resistance [88]. Furthermore, the prevalence of hepatic steatosis has been reported to be greater in Hispanics and lower in AA compared with EA [89]. In AA, lower IHCL content can be explained by the decrease in visceral fat, and is observed despite higher rates of obesity and insulin resistance [90]. The ethnic differences in the frequency of hepatic steatosis mirror those reported for NAFLD-related cirrhosis [91], indicating that ethnicity may have a profound impact on susceptibility to the broad range of steatosis-related liver disease. Overall, these studies indicate that independent of obesity, increased IHCL identifies a subset of individuals at increased risk of type 2 diabetes and cardiovascular disease, although these relationships are affected by ethnicity. The aggregate of data in AA highlight differences in the pathogenesis of the IRS and the metabolic traits that cluster with insulin resistance.

Importantly, while IMCL and IHCL accumulation is linked to insulin resistance and multiple components of the IRS in EA, these studies indicate that ectopic fat accumulation is not an indispensable feature of insulin resistance in AA. 


\section{Conclusions}

The relationships between insulin resistance, IMCL, and IHCL are complex and vary according to diet, exercise, weight loss, and racial identity. Overall, there is a high degree of association of both IMCL and IHCL with insulin resistance and the associated cluster of cardiometabolic risk factors; although African ancestry may affect these relationships. Factors intrinsic to adipose tissue function and architecture, and the influence of adipose tissue on lipid accumulation in non-adipose tissue compartments, are likely important in explaining these associated differences. Further research is needed to determine the orchestrated roles of adipose and non-adipose tissue compartments in the regulation of insulin sensitivity, and mechanisms explaining racial differences in the IRS trait cluster.

\section{Acknowledgements}

This work was supported from grants from the National Institutes of Health DK-38764 (WTG), PO1 HL-55782 (WTG), and the T32 training grant (HL-007457) entitled "Mechanisms of Hypertension and Cardiovascular Diseases (PI: S. Oparil), and by the Merit Review program of the Department of Veterans Affairs (WTG). We also acknowledge support from the UAB General Clinical Research Center M01-RR00032, and the research core facilities of the Clinical Nutrition Research Unit (P30 DK56336) and the Diabetes Research and Training Center (P60 DK079626) at UAB. Finally, we are grateful to the research volunteers for their participation.

\section{References}

1. Grundy SM, Cleeman JI, Daniels SR, et al. Diagnosis and management of the metabolic syndromes. Circulation 2005;112:735-752.

2. Reaven GM. Pathophysiology of insulin resistance in human disease. Physiology Reviews 1995;75:473-486.

3. Liao Y, Kwon S, Shaughnessy S, et al. Critical evaluation of adult treatment panel III criteria in identifying insulin resistance with dyslipidemia. Diabetes Care 2004;27(4):978-983. [PubMed: 15047659]

4. Festa A, D'Agostino R Jr, Howard G, et al. Chronic subclinical inflammation as part of the insulin resistance syndrome: the Insulin Resistance Atherosclerosis Study (IRAS). Circulation 2000;102(1): 42-47. [PubMed: 10880413]

5. Lara-Castro C, Luo N, Wallace P, et al. Adiponectin multimeric complexes and the metabolic syndrome trait cluster. Diabetes 2006;55:249-59. [PubMed: 16380500]

6. Grundy SM. Metabolic syndrome: a multiplex cardiovascular risk factor. J Clin Endocrinol Metab 2007;92:399-404. [PubMed: 17284640]

7. Lara-Castro C, Garvey WT. Diet, insulin resistance, and obesity: zoning in on data for Atkins dieters living in South Beach. J Clin Endocrinol Metab 2004;89:4197-205. [PubMed: 15356006]

8. Paradisi G, Smith L, Burtner C, Leaming R, Garvey WT, Hook G, Johnson A, Cronin J, Steinberg HO, Baron AD. Dual energy X-ray absorptiometry assessment of fat mass distribution and its association with the insulin resistance syndrome. Diabetes Care 1999;22:1310-1317. [PubMed: 10480776]

9. Groop LC, Saloranta C, Shank M, et al. The role of free fatty acid metabolism in the pathogenesis of insulin resistance in obesity and noninsulin-dependent diabetes mellitus. J Clin Endocrinol Metab 1991;72:96-107. [PubMed: 1986032]

10. Kelley DE. Skeletal muscle fat oxidation: timing and flexibility are everything. J Clin Invest 2005;115:1699-1702. [PubMed: 16007246]

11. Savage DB, Petersen KF, Shulman GI. Mechanisms of insulin resistance in humans and possible links with inflammation. Hypertension 2005;45:828-833. [PubMed: 15824195]

12. Yki-Jarvinen H, Puhakainen I, Saloranta C, et al. Demonstration of a novel feedback mechanism between FFA oxidation from intracellular and intravascular sources. Am J Physiol 1991;260:E680E689. [PubMed: 2035624]

13. Carlson LA, Ekelund LG, Froberg SO. Concentration of triglycerides, phospholipids, and glycogen in skeletal muscle and of free fatty acids and beta-hydroxybutyric acid in blood in man in response to exercise. Eur J Clin Invest 1971;1:248-254. [PubMed: 5549529] 
14. Pan DA, Lillioja S, Kriketos AD, et al. Skeletal muscle triglyceride levels are inversely related to insulin action. Diabetes 1997;46:983-988. [PubMed: 9166669]

15. Colberg SR, Simoneau JA, Thaete FL, et al. Skeletal muscle utilization of free fatty acids in women with visceral obesity. J Clin Invest 1994;95:1846-1853. [PubMed: 7706491]

16. Simoneau JA, Colberg SR, Thaete FL, et al. Skeletal muscle glycolytic and oxidative enzyme capacities are determinants of insulin sensitivity and muscle composition in obese women. FASEB J 1995;9:273-278. [PubMed: 7781930]

17. Kelley DE, Simoneau JA. Impaired free fatty acid utilization by skeletal muscle in non-insulindependent diabetes mellitus. J Clin Invest 1994;94:2349-2356. [PubMed: 7989591]

18. Falholt K, Jenson I, Lindkaer-Jensen S, et al. Carbohydrate and lipid metabolism of skeletal muscle in type 2 diabetic patients. Diabet Med 1988;1:27-31. [PubMed: 2964324]

19. Froberg SO. Muscle triglycerides: relation to glycogen in muscle and plasma triglycerides in men of different ages. Acta Med Scand 1973;193:463-468. [PubMed: 4717326]

20. Froberg SO. Concentration of cholesterol and triglycerides in skeletal muscle of healthy men and myocardial infarction patients. Acta Med Scand 1973;194:553-558. [PubMed: 4773456]

21. Schick F, Eismann B, Jung WI, et al. Comparison of localized proton NMR signals of skeletal muscle and fat tissue in vivo: two lipid compartments in muscle tissue. Magn Reson Med 1993;29:158-167. [PubMed: 8429779]

22. Rico-Sanz J, Hajnal JV, Thomas EL, et al. Intracellular and extracellular sleletal muscle triglyceride metabolism during alternating intensity exercise in humans. J Physiol 1998;510:615-622. [PubMed: 9706008]

23. Jacob S, Machaan J, Rett K, et al. Association of increased intramyocellular lipid content with insulin resistance in lean nondiabetic offspring of type 2 diabetic subjects. Diabetes 1999;48:1113-1119. [PubMed: 10331418]

24. Goodpaster BH, Thaete FL, Simoneau JA, et al. Subcutaneous abdominal fat and thigh muscle composition predict insulin sensitivity indeoendently of visceral fat. Diabetes 1997;46:1579-1585. [PubMed: 9313753]

25. Storlien LH, Oakes ND, Pan DA, et al. Syndromes of insulin resistance in the rat: inducement by diet and amelioration with benfluorex. Diabetes 1993;42:457-462. [PubMed: 8432416]

26. Chen MT, Kaufman LN, Spennetta T, et al. Effects of high-rat feeding to rats on the interrelationship of body weight, plasma insulin, and fatty acyl-coenzyme A esters in liver and skeletal muscle. Metabolism 1992;41:564-569. [PubMed: 1588840]

27. Shillabeer G, Chamoun C, Hatch G, et al. Exogenous triacylglyercol inhibits insulin-stimulated glucose transport in L6 muscle cells in vitro. Biochem Biophys Res Commun 1995;207:768-774. [PubMed: 7864871]

28. Saha AK, Kurowski TG, Colca JR, et al. Lipid abnormalities in tissues of the KKA ${ }^{\mathrm{y}}$ mouse: effects of pioglitazone on malyonyl CoA and diacylglycerol. Am J Physiol 1994;267:E95-E101. [PubMed: 8048519]

29. Schrauwen-Hinderling VB, Schrauwen P, Hesselink MK, van Engelshoven JM, Nicolay K, Saris WH, Kessels AG, Kooi ME. The increase in intramyocellular lipid content is a very early response to training. J Clin Endocrinol Metab 2003;88:1610-1616. [PubMed: 12679446]

30. Helge J, Dela F. Effect of training on muscle triacylglycerol and structural lipids: a relationship to insulin sensitivity? Diabetes 2003;52:1881-1887. [PubMed: 12882901]

31. Taylor CR, Hoppeler H, Kennedy C, Valenski T, Roberts TJ, Weyand P. High fat diet improves aerobic performance by building mitochondria. Physiologist 1994;37:A84.

32. He J, Goodpaster BH, Kelley DE. Effects of weight loss and physical activity on muscle lipid content and droplet size. Obesity Res 2004;12:761-769.

33. Boden G, Lebed B, Schatz M, et al. Effects of acute changes of plasma free fatty acids on intramyocellular fat content and insulin resistance in healthy subjects. Diabetes 2001;50:1612-1617. [PubMed: 11423483]

34. Bachmann OP, Dahl DB, Brechtel K, et al. Effects of Intravenous and Dietary Lipid Challenge on Intramyocellular Lipid Content and the Relation With Insulin Sensitivity in Humans. Diabetes 2001;50:2579-2584. [PubMed: 11679437] 
35. Greco AV, Mingrone G, Giancaterini A, et al. Insulin resistance in morbid obesity: reversal with intramyocellular fat depletion. Diabetes 2002;51:144-151. [PubMed: 11756334]

36. Fabris R, Mingrone G, Milan G, et al. Further lowering of muscle lipid oxidative capacity in obese subjects after biliopancreatic diversion. J Clin Endocrinol Metab 2004;89:1753-1759. [PubMed: 15070941]

37. Goodpaster BH, Theriault R, Watkins SC, Kelley DE. Intramuscular lipid content is increased in obesity and decreased by weight loss. Metabolism 2000;49:467-472. [PubMed: 10778870]

38. Lara-Castro C, Newcomer BR, Rowell J, et al. Effects of short-term very low-calorie diet on intramyocellular lipid and insulin sensitivity in nondiabetic and type 2 diabetic subjects. Metabolism 2008;57:1-8. [PubMed: 18078853]

39. Kelley DE, He J, Menshikova EV, et al. Dysfunction in mitochondria in human skeletal muscle in type 2 diabetes. Diabetes 2002;51:2944-2950. [PubMed: 12351431]

40. Petersen KF, Dufour S, Befroy D, et al. Impaired mitochondrial activity in the insulin-resistant offspring of patients with type 2 diabetes. N Engl J Med 2004;350:664-671. [PubMed: 14960743]

41. Petersen KF, Befroy D, Dufour S, et al. Mitochondrial dysfunction in the elderly: possible role in insulin resistance. Science 2003;300:1140-1142. [PubMed: 12750520]

42. Fromenty B, Robin MA, Igoudjil A, et al. The ins and outs of mitochondrial dysfunction in NASH. Diabetes Metab 2004;30:121-138. [PubMed: 15223984]

43. Patti ME, Butte AJ, Crunkhorn S, et al. Coordinated reduction of genes of oxidative metabolism in humans with insulin resistance and diabetes: Potential role of PGC1 and NRF1. Proc Natl Acad Sci U S A 2003;100:8466-8471. [PubMed: 12832613]

44. Sreekumar R, Halvatsiotis P, Schimke JC, et al. Gene expression profile in skeletal muscle of type 2 diabetes and the effect of insulin treatment. Diabetes 2002;51:1913-1920. [PubMed: 12031981]

45. Yang X, Pratley RE, Tokraks S, et al. Microarray profiling of skeletal muscle tissues from equally obese, non-diabetic insulin-sensitive and insulin-resistant Pima Indians. Diabetologia 2002;45:15841593. [PubMed: 12436343]

46. Wu X, Moellering D, Vestri H, et al. Dysregulation of Mitochondria-Related Genes and Transcription Factors Involved in Mitochondrial Biogenesis in Skeletal Muscle from Insulin Resistant Humans. Diabetes 2005;54(Suppl 2):A273.

47. Moellering DR, Ulasova E, Landar AL, Vestri HS, Wallace P, Darley-Usmar V, Garvey WT. Proteomic Analysis of Skeletal Muscle Mitochondria in Type 2 Diabetes Reveals Altered Concentrations and Oxidation of Respiratory Chain Proteins. Diabetes 2005;54(Suppl 2):A58.

48. Toledo FG, Menshikova EV, Azuma K, et al. Mitochondrial capacity in skeletal muscle is not stimulated by weight loss despite increases in insulin action and decreases in intramyocellular lipid content. Diabetes 2008;57(4):987-94. [PubMed: 18252894]

49. Ruhl CE, Everhart JE. Determinants of the association of overweight with elevated serum alanine aminotransferase activity in the United States. Gastroenterology 2003;124:71-79. [PubMed: 12512031]

50. Adams LA, Lymp JF, St Sauver J, et al. The natural history of nonalcoholic fatty liver disease: a population-based cohort study. Gastroenterology 2005;129:113-121. [PubMed: 16012941]

51. Park SH, Kim BI, Kim SH, et al. Body fat distribution and insulin resistance: beyond obesity in nonalcoholic fatty liver disease among overweight men. J Am Coll Nutr 2007;26:321-326. [PubMed: 17906183]

52. Deivanayagam S, Mohammed BS, Vitola BE, et al. Nonalcoholic fatty liver disease is associated with hepatic and skeletal muscle insulin resistance in overweight adolescents. Am J Clin Nutr 2008;88:257-262. [PubMed: 18689359]

53. Musso C, Cochran E, Moran SA, et al. Clinical course of genetic diseases of the insulin receptor (type A and Rabson-Mendenhall syndromes): a 30-year prospective. Medicine 2004;83:209-222. [PubMed: 15232309]

54. Cochran E, Young JR, Sebring N, et al. Efficacy of recombinant methionyl human leptin therapy for the extreme insulin resistance of the Rabson-Mendenhall syndrome. J Clin Endocrinol Metab 2004;89:1548-1554. [PubMed: 15070911]

55. Maeda N, Shimomura I, Kishida K, et al. Diet-induced insulin resistance in mice lacking adiponectin/ ACRP30. Nat Med 2002;8:731-737. [PubMed: 12068289] 
56. Yano W, Kubota N, Itoh S, et al. Molecular mechanism of moderate insulin resistance in adiponectinknockout mice. Endocr J 2008;55:515-522. [PubMed: 18446001]

57. Weisberg SP, McCann D, Desai M, et al. Obesity is associated with macrophage accumulation in adipose tissue. J Clin Invest 2003;112:1796-1808. [PubMed: 14679176]

58. Bruun JM, Helge JW, Richelsen B, et al. Diet and exercise reduce low-grade inflammation and macrophage infiltration in adipose tissue but not in skeletal muscle in severely obese subjects. Am J Physiol Endocrinol Metab 2006;90:E961-967. [PubMed: 16352667]

59. Unger RH. Lipotoxic diseases. Annu Rev Med 2002;53:319-336. [PubMed: 11818477]

60. Ebihara K, Kusakabe T, Hirata M, et al. Efficacy and safety of leptin-replacement therapy and possible mechanisms of leptin actions in patients with generalized lipodystrophy. J Clin Endocrinol Metab 2007;92:532-541. [PubMed: 17118991]

61. Bajaj M, Suraamornkul S, Pratipanawatr T, et al. Pioglitazone reduces hepatic fat content and augments splanchnic glucose uptake in patients with type 2 diabetes. Diabetes 2003;52:1364-1370. [PubMed: 12765945]

62. Tontonoz P, Hu E, Spiegelman BM. Stimulation of adipogenesis in fibroblasts by PPAR gamma 2, a lipid-activated transcription factor. Cell 1994;79:1147-1156. [PubMed: 8001151]

63. Crossno JT Jr, Majka SM, Grazia T, et al. Rosiglitazone promotes development of a novel adipocyte population from bone marrow-derived circulating progenitor cells. J Clin Invest 2006;116:3220 3228. [PubMed: 17143331]

64. Iglesias P, Alvarez Fidalgo P, Codoceo R, et al. Lipoatrophic diabetes in an elderly woman: clinical course and serum adipocytokine concentrations. Endocr J 2004;51:279-286. [PubMed: 15256772]

65. Sevastianova K, Sutinen J, Kannisto K, et al. Adipose tissue inflammation and liver fat in patients with highly active antiretroviral therapy-associated lipodystrophy. Am J Physiol Endocrinol Metab 2008;295:E85-91. [PubMed: 18430964]

66. Sopasakis VR, Sandqvist M, Gustafson B, et al. High local concentrations and effects on differentiation implicate interleukin-6 as a paracrine regulator. Obes Res 2004;12:454-460. [PubMed: 15044662]

67. Gustafson B, Smith U. Cytokines promote Wnt signaling and inflammation and impair the normal differentiation and lipid accumulation in 3T3-L1 preadipocytes. J Biol Chem 2006;281:9507-9516. [PubMed: 16464856]

68. Fu Y, Luo N, Klein RL, et al. Adiponectin promotes adipocyte differentiation, insulin sensitivity, and lipid accumulation. J Lipid Res 2005;46:1369-1379. [PubMed: 15834118]

69. Makkonen J, Westerbacka J, Kolak M, et al. Increased expression of the macrophage markers and of 11beta-HSD-1 in subcutaneous adipose tissue, but not in cultured monocyte-derived macrophages, is associated with liver fat in human obesity. Int J Obes 2007;31:1617-1625.

70. Kolak M, Westerbacka J, Velagapudi VR, et al. Adipose tissue inflammation and increased ceramide content characterize subjects with high liver fat content independent of obesity. Diabetes 2007;56:1960-1968. [PubMed: 17620421]

71. Bell M, Wang H, Chen H, et al. Consequences of lipid droplet coat protein downregulation in liver cells: abnormal lipid droplet metabolism and induction of insulin resistance. Diabetes 2008;57:20372045. [PubMed: 18487449]

72. Tansey JT, Sztalryd C, Gruia-Gray J, et al. Perilipin ablation results in a lean mouse with aberrant adipocyte lipolysis, enhanced leptin production, and resistance to diet-induced obesity. Proc Natl Acad Sci U S A 2001;98:6494-6499. [PubMed: 11371650]

73. Martinez-Botas J, Anderson JB, Tessier D, et al. Absence of perilipin results in leanness and reverses obesity in Lepr(db/db) mice. Nat Genet 2000;26:474-479. [PubMed: 11101849]

74. Reue K, Zhang P. The lipin protein family: dual roles in lipid biosynthesis and gene expression. FEBS Lett 2008;582:90-96. [PubMed: 18023282]

75. Peterfy M, Phan J, Xu P, et al. Lipodystrophy in the fld mouse results from mutation of a new gene encoding a nuclear protein, lipin. Nat Genet. 2001

76. Suviolahti E, Reue K, Cantor RM, et al. Cross-species analyses implicate Lipin 1 involvement in human glucose metabolism. Hum Mol Genet 2006;15:377-386. [PubMed: 16357106] 
77. Yao-Borengasser A, Rasouli N, Varma V, et al. Lipin expression is attenuated in adipose tissue of insulin-resistant human subjects and increases with peroxisome proliferator-activated receptor gamma activation. Diabetes 2006;55:2811-2818. [PubMed: 17003347]

78. Wild S, Roglic G, Green A, et al. Global prevalence of diabetes - Estimates for the year 2000 and projections for 2030. Diabetes Care 2004;27:1047-1055. [PubMed: 15111519]

79. Brancati FL, Kao WHL, Folsom AR, et al. Incident type 2 diabetes mellitus in African American and white adults - The atherosclerosis risk in communities study. JAMA 2000;2253:2259.

80. Harris MI. Noninsulin-dependent diabetes mellitus in black and white Americans. Diabetes Metab Rev 1990;6:71-90. [PubMed: 2198151]

81. Lovejoy JC, de la Bretonne JA, Klemperer M, et al. Abdominal fat distribution and metabolic risk factors: effects of race. Metabolism 1996;45:1119-1124. [PubMed: 8781299]

82. Lara-Castro C, Weinsier RL, Hunter GR, et al. Visceral adipose tissue in women: longitudinal study of the effects of fat gain, time, and race. Obes Res 2002;10:868-874. [PubMed: 12226134]

83. Weinsier RL, Hunter GR, Gower BA, et al. Body fat distribution in white and black women: different patterns of intraabdominal and subcutaneous abdominal adipose tissue utilization with weight loss. Am J Clin Nutr 2001;74:631-636. [PubMed: 11684531]

84. Gower BA, Nagy TR, Goran MI. Visceral fat, insulin sensitivity, and lipids in prepubertal children. Diabetes 1999;48:1515-1521. [PubMed: 10426367]

85. van der Merwe MT, Crowther NJ, Schlaphoff GP, et al. Evidence for insulin resistance in black women from South Africa. Int J Obes Relat Metab Disord 2000;24:1340-1346. [PubMed: 11093297]

86. Stein E, Kushner H, Gidding S, et al. Plasma lipid concentrations in nondiabetic African American adults: associations with insulin resistance and the metabolic syndrome. Metabolism 2007;56:954960. [PubMed: 17570258]

87. Gower BA, Fernandez JR, Beasley TM, et al. Using genetic admixture to explain racial differences in insulin-related phenotypes. Diabetes 2003;52:1047-1051. [PubMed: 12663479]

88. Heimburger K, Lara-Castro C, Newcomer B. Obesity. 2007

89. Giday SA, Ashiny Z, Naab T, et al. Frequency of nonalcoholic fatty liver disease and degree of hepatic steatosis in African-American patients. J Natl Med Assoc 2006;98:1613-1615. [PubMed: 17052050]

90. Browning JD, Kumar KS, Saboorian MH, et al. Ethnic differences in the prevalence of cryptogenic cirrhosis. Am J Gastroenterol 2004;99:292-298. [PubMed: 15046220]

91. Browning JD, Szczepaniak LS, Dobbins R, et al. Prevalence of hepatic steatosis in an urban population in the United States: impact of ethnicity. Hepatology 2004;40:1387-1395. [PubMed: 15565570] 
A.

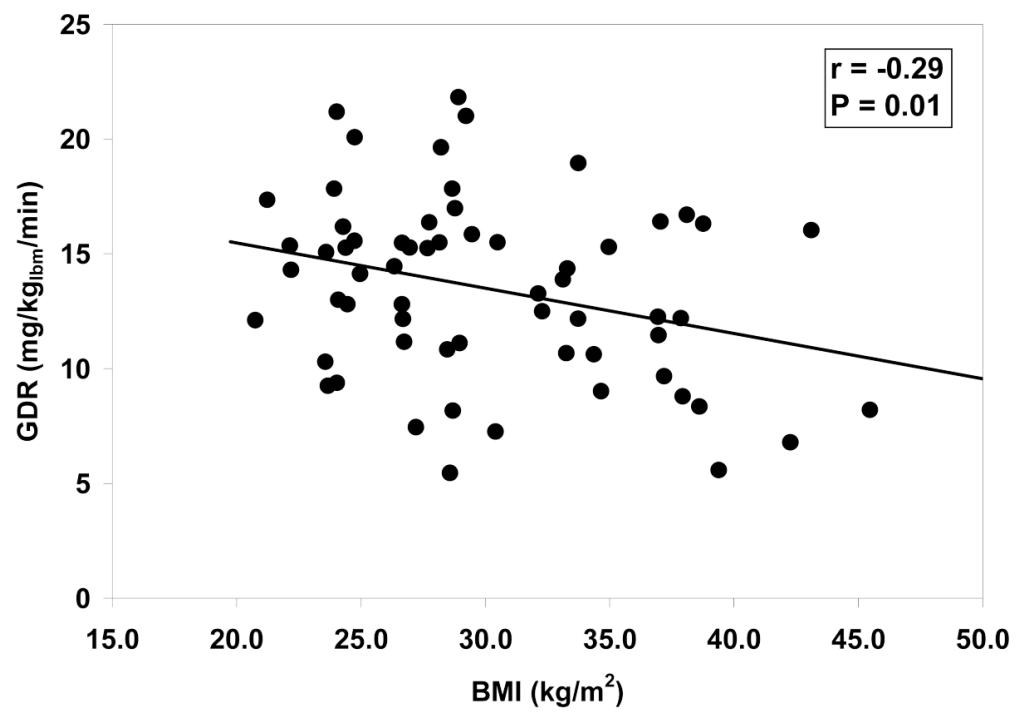

B.

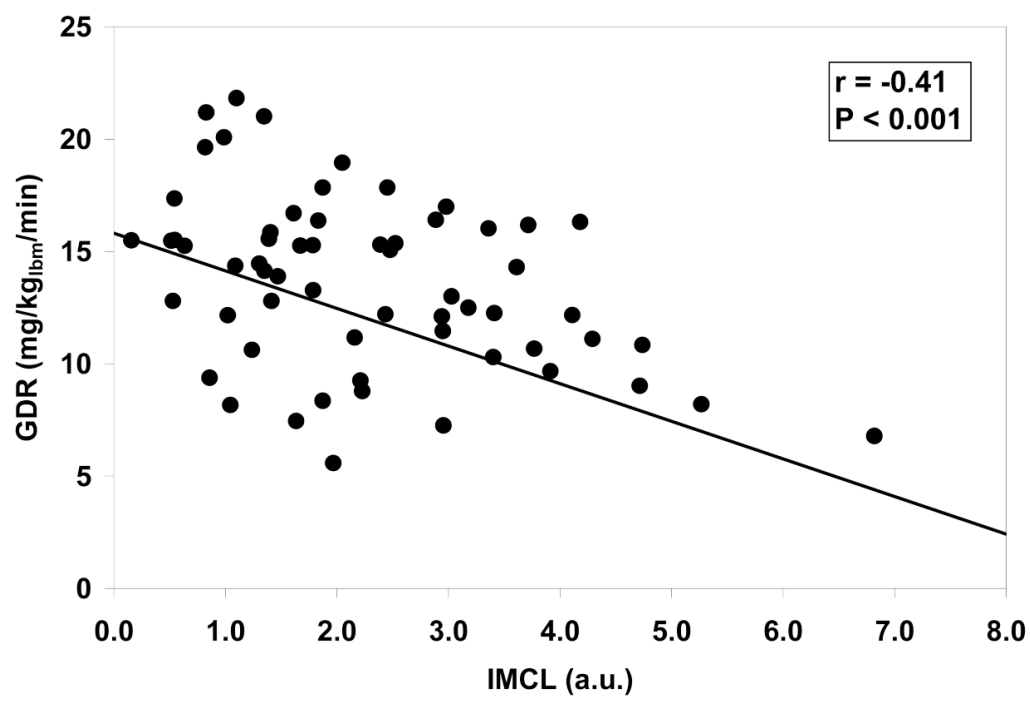

Endocrinol Metab Clin North Am. Author manuscript; available in PMC 2009 December 1. 
C.

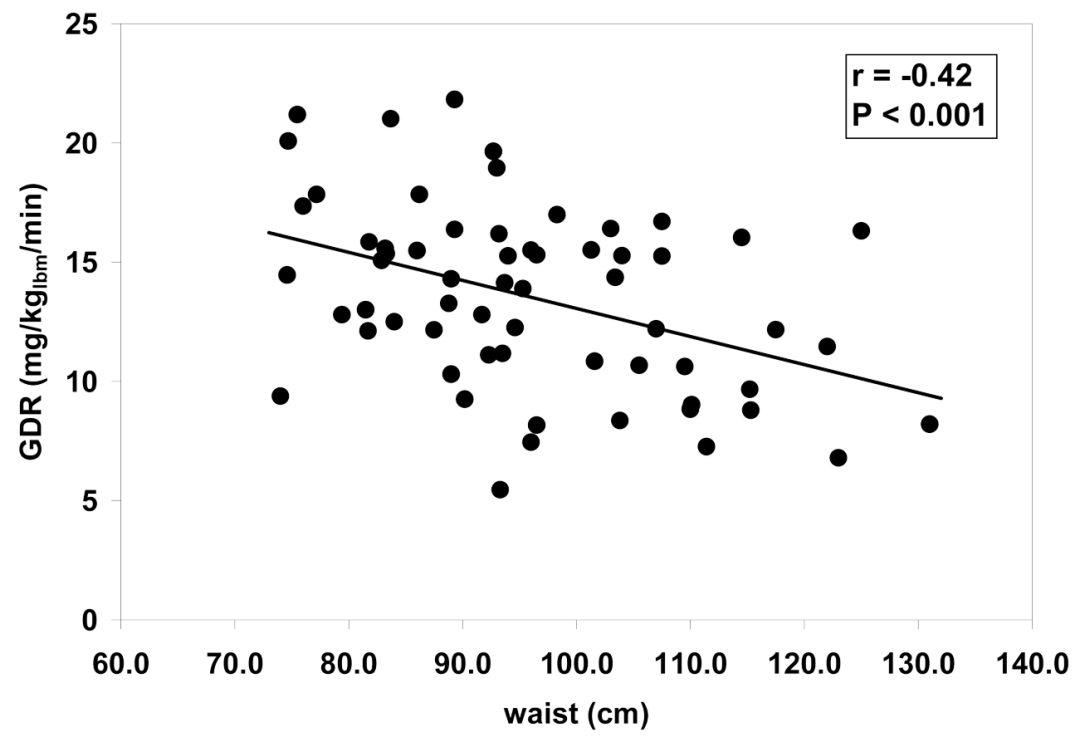

Figure 1.

Relationships between measures of insulin-stimulated glucose disposal rate (GDR) and general adiposity (body mass index = BMI), panel A; and intramyocellular lipid (IMCL), panel B; and waist circumference, panel $\mathrm{C}$. 

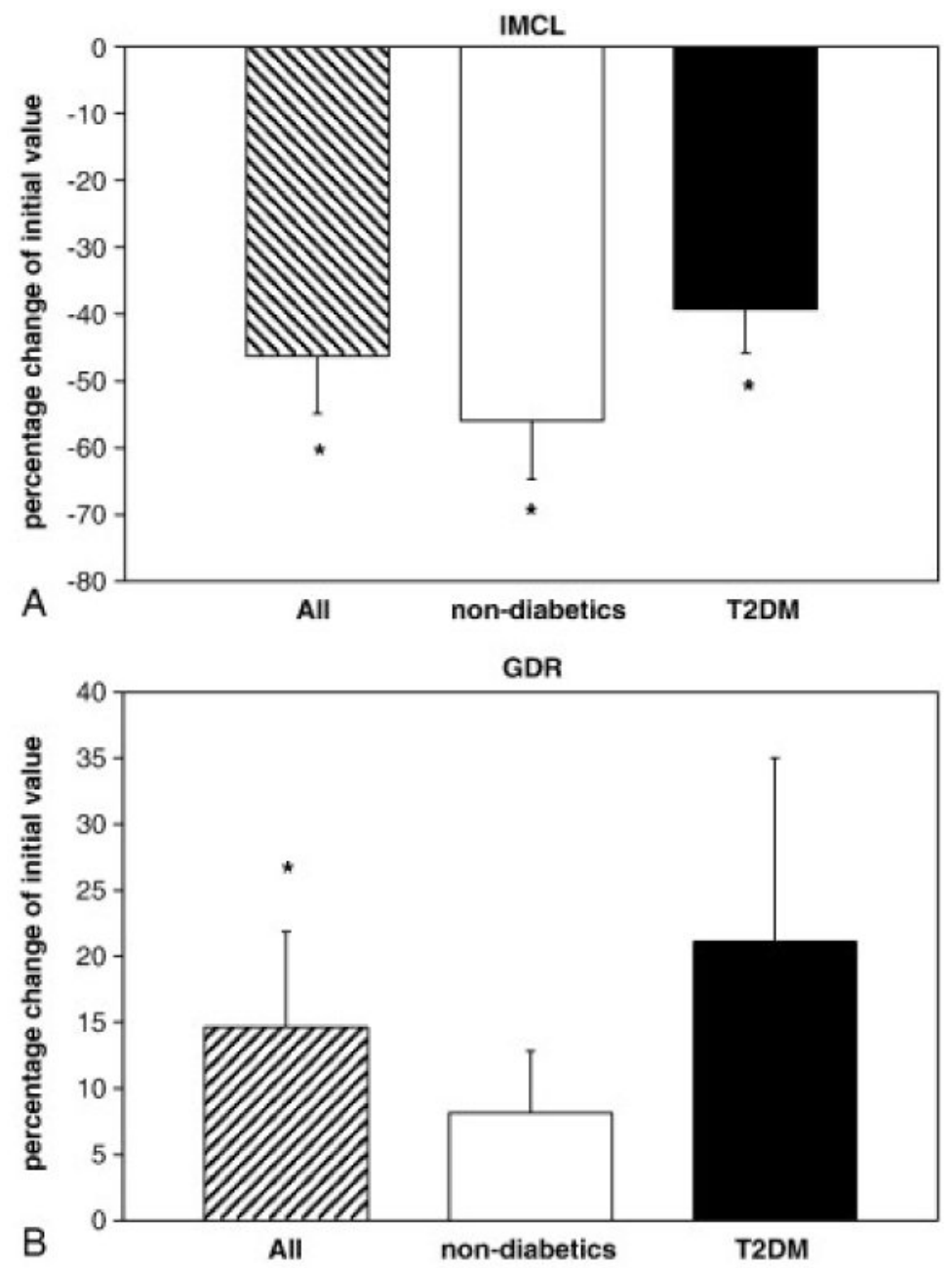

Figure 2.

Percent change in IMCL (top panel) and GDR (bottom panel) in non-diabetic and type 2 diabetic subjects after short-term very-low calorie diet. Intramyocellular lipid was assessed in the soleus muscle of each individual using proton nuclear magnetic resonance spectroscopy, and GDR was assessed using the euglycemic-hyperinsulinemic glucose clamp technique. ${ }^{*} \mathrm{P}$ $<.05$, significantly different from baseline values. From Lara-Castro et al. Metabolism 2008, with permission [38]. 
A.

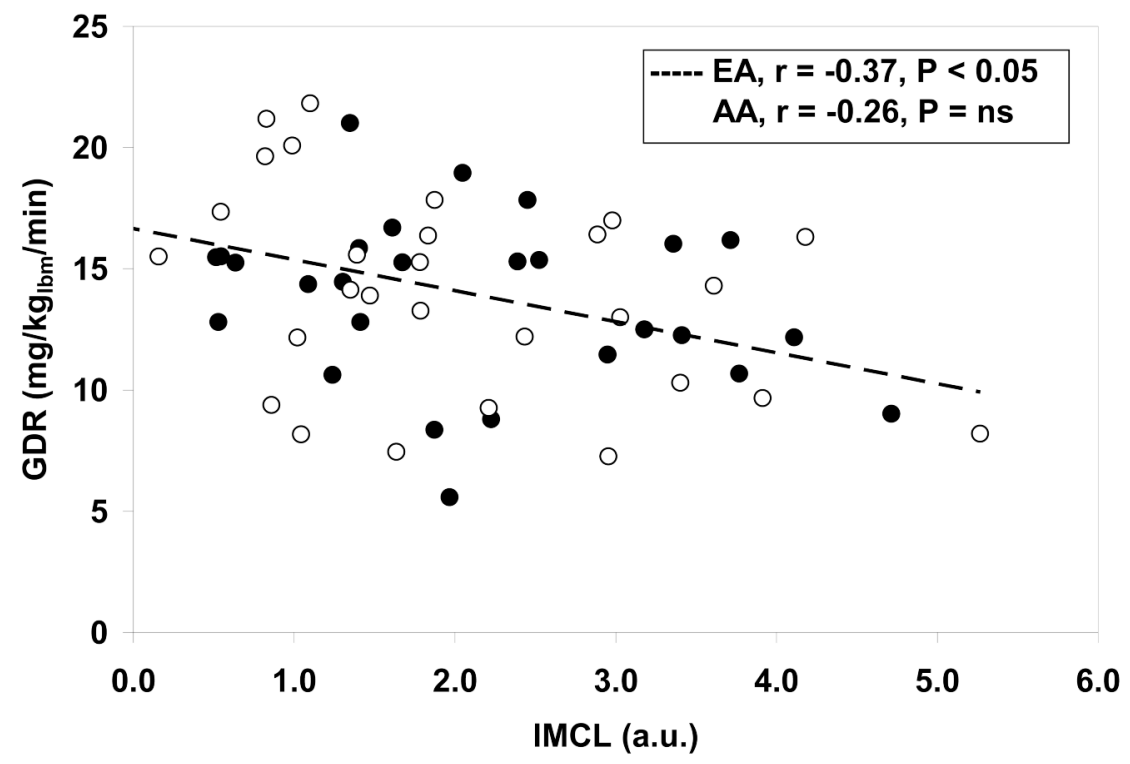

B.

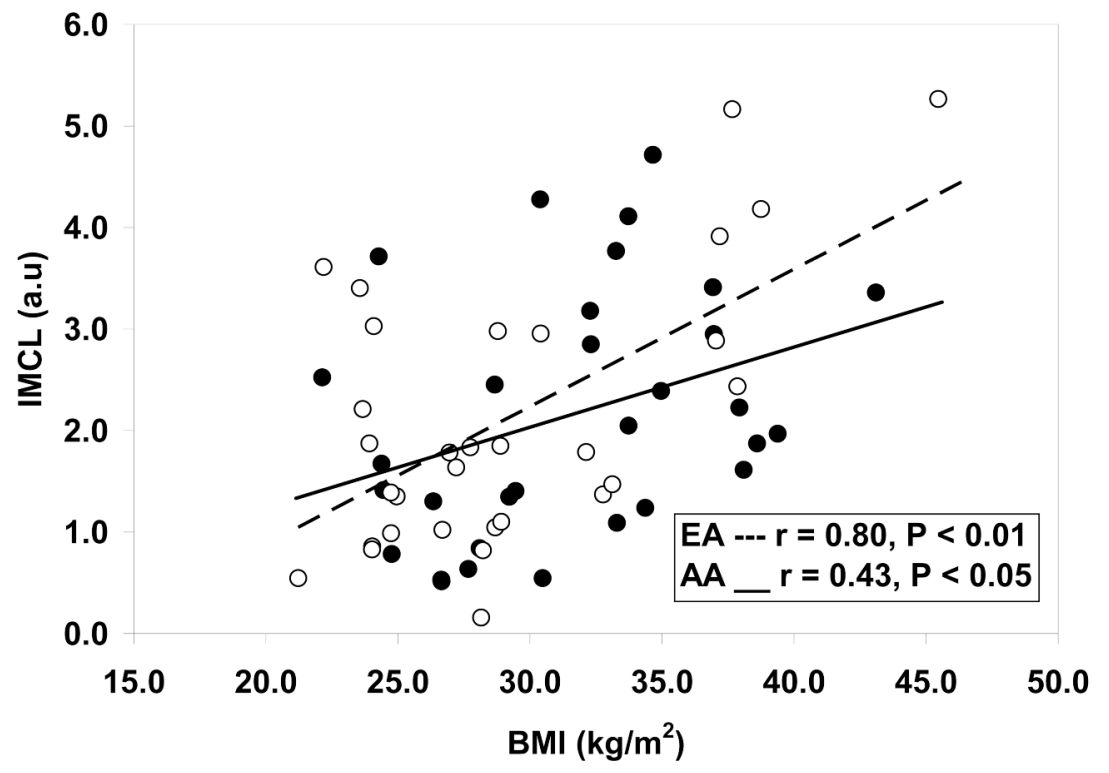

Figure 3.

Relationships between intramyocellular lipid (IMCL) and insulin stimulated glucose disposal rate (GDR), panel A, and body mass index (BMI), panel B, in African-American (AA, filled circles) and European-American (EA, empty circles). 